\title{
Fotobiyoreaktörde Işı̆̆ı̀n ve Beslemenin Alglerin Büyümeleri Üzerine Etkilerinin Araştırılması
}

\author{
Nergiz Uçmaz ${ }^{1}$, Batuhan Sert ${ }^{1}$, Cemalettin Aygün ${ }^{2}$, Oğuz Yunus Sarıbıyık ${ }^{1 *}$ \\ 1* Gümüşhane Üniversitesi, Mühendislik ve Doğa BilimleriFakültesi, Genetik ve Biyomühendislik Bölümü, Gümüşhane, Türkiye, (ORCID: 0000-0001-9735-8735), \\ oysaribiyik@gumushane.edu.tr \\ ${ }^{2}$ Karadeniz Teknik Üniversitesi, Deniz Bilimleri Fakültesi, Gemi Makinaları İşletme Mühendisliği Bölümü, Trabzon, Türkiye (ORCID: 0000-0002-6033-3558), \\ caygun@ktu.edu.tr
}

(İlk Geliş Tarihi 12 Ocak 2021 ve Kabul Tarihi 5 Nisan 2021)

(DOI: 10.31590/ejosat.859107)

ATIF/REFERENCE: Uçmaz, N., Sert, B., Aygün, C. \& Sarıbıyık, O. Y. (2021). Fotobiyoreaktörde Işı̆̆ın ve Beslemenin Alglerin Büyümeleri Üzerine Etkilerinin Araştırılması. Avrupa Bilim ve Teknoloji Dergisi, (23), 475-480.

\section{$\ddot{O} \mathbf{z}$}

Dünya nüfusunun çoğalmasına bağlı olarak gıda ve enerji ihtiyaçları da artmaktadır. Enerji ve gıda tüketimi karbondioksit salınım miktarının yükselmesi ile yakından alakalıdır. Karbondioksit miktarının artması Sera gazı etkisi göstererek küresel ısınmaya sebep olmakta böylece doğal afetler yaşanmaktadır. Sera gazı etkisinin azaltılması için fosil kaynaklara alternatif enerji kaynakları bulunmalı ve atıkların sürdürülebilir şekilde kontrol edilerek geri dönüşüme kazandırılması gerekmektedir. Alternatif enerji kaynakları olarak biyogaz, biyodizel, güneş enerjisi gibi yenilenebilir enerji kaynakları yoğun şekilde araştırılmaktadır. Algler, alternatif gıda ve enerji ihtiyacını karşılamak için araştırılan kaynaklar arasında yer almaktadır. Bu canlılar, genel olarak ökaryotik fotosentez yapabilen canlıların genel tanımlamasıdır ve bu sınıf içerisinde çok farklı alt türleri bulunmaktadır. Yapılan çalışmalarda, 1 kg kuru alg oluşumu sırasında $1.83 \mathrm{~kg} \mathrm{CO}_{2}$ tükettiği, yağ protein kaynağı ve organik gübre olarak kullanılabildiği görülmüştür. $\mathrm{CO}_{2}$ tüketim miktarının yüksek olması, alternatif besin ve yenilenebilir enerji kaynağı gibi farklı amaçlar için kullanılma potansiyelinden dolayı Alglerin uygun yaşam alanlarının belirlenmesi gerekmektedir.

Yapılan bu çalışmada, hava karıştırmalı kolon tipi pilot fotobiyoreaktör imalatı yapılmıştır model alg üzerinde, 1şığın ve beslenmenin büyüme üzerine etkileri araştırılmıştır. Model alg olarak "Cladhopora glomerata" kullanılmıştır. Besleme için, inorganik tuzlar, \%17'lik doğal kaynaklardan elde edilen amino asit çözeltisi ve $425 \mathrm{~nm}$ dalga boyuna sahip 1şı̆̆ın alglerdeki kütle artışı üzerine etkileri araştırılmıştır. Elde edilen sonuçlar, alglerin $425 \mathrm{~nm}$ dalga boyundaki (mor 1şık) kütle artışı gün 1şığındaki 1şığa göre kıyaslandığında daha fazla kütle artışı gözlemlenmiştir. Bunun dışında alglerin kütle artışı beslemelerine göre kıyaslandığında \%17 lik doğal amino asit kaynağı ile besleme yapıldığında inorganik tuzlara göre kütlece artışının daha fazla olduğu gözlemlenmiştir.

Anahtar Kelimeler: Fotobiyoreaktör, Cladhopora glomerata, Biyoyakıt.

\section{The Effect of the Light and Feeding on Growth of Algea in Bioreactor}

\begin{abstract}
The energy and food requirements have been increased depending on the growth of the world populations. The consumption of the food and energy cause for rising the carbon dioxide emissions. The increase of the greenhouse gases develops global warming therefore natural disaster occurred. In order to decrease of the effect of the greenhouse gases, the waste should sustainably be controlled and they should be managed for recycling. In consequence, such as an alternative energy resources biodiesel, wind power, biogas, sun have intensively been investigated. Algaes have been considered as an alternative sources supplier for investigating food stock and energy requirements. Algae is a general definition of organism can make a eukaryotic photosynthesis, and there are many sub-species in this class. In previous studies, $1.83 \mathrm{~kg}$ of $\mathrm{CO}_{2}$ have been consumed for production of $1 \mathrm{~kg}$ of dry algae and they can be used as fertilizer or bio-oil sources. Therefore, appropriate habitats of Algea along with the various features is necessary to investigate.

In this study, the two air bubble column type pilot scale photo-bio reactor $4 \mathrm{~L}$ were designed for investigation of optimum living condition for "Cladhopora glomerata". Moreover, the effect of different feeding such as inorganic salts, and 17 percent natural amino acids were investigated on the growth of Algea. The results showed that the algae have developed their weight better at the $425 \mathrm{~nm}$ wavelength (purple light) compared to daylight. Also, 17 percent natural amino acid is better than the inorganic salts.
\end{abstract}

Keywords: Photo-bioreactor, Cladhopora glomerata, Biofuel.

\footnotetext{
*Sorumlu Yazar: oysaribiyik@gumushane.edu.tr
} 


\section{Giriş}

Dünya nüfusunun artmasına ve teknolojinin gelişimine bağlı olarak enerji ve gida tüketimi $\operatorname{artmaktadır(K.~M.~Nazmul~et~al.,~}$ 2021). Enerji talebini karşılamak üzere kullanılan fosil kaynaklı yakıtlardan oluşan karbondioksit istatiklere göre 1900 yılında 290 ppm iken 2021 yılı verilerine göre 410 ppm olarak ölçülmüştür(Lindsey, 2021). Bu farklılık küresel ısınmanın artmasına sebep olurken bunun yanısıra ormanlık alanların azalması kuraklık, sel vb. çeşitli doğal afetlerin gözle görülür şekilde canlıları etkilemesine sebep olmaktadır (Corrie \& Fernando, 2020; JeanCalleja et al., 2020; Yaduvanshi et al., 2021). Meydana gelen doğal afetlere bağlı olarak gıda üretimi de etkilenerek azalmakta böylece süreç bir kısır döngü haline gelmektedir(Shuirong et al., 2021). Küresel 1sinmay1 kontrol altına alabilmek ve doğaya salınan karbondioksit miktarının azaltılması için alternatif yenilenebilir çözümlere ihtiyaç duyulmaktadır. Güneş enerjisi, biyodizel, biyogaz, rüzgâr, dalga enerjisi gibi alternatif yenilenebilir enerji kaynaklarının sürdürülebilir olması küresel ısınmanın etkilerini azaltarak dünya ekosisteminin tekrar düzeltilebilmesine olanak sağlamaktadır(Bedoi et al., 2020; Oğuz Yunus et al., 2010; Patel et al., 2020; Zhang et al., 2020; Zhoua et al., 2021). Alternatif kaynakların eldesinde küresel 1sınmaya sebep olan karbondioksitin Sera gazı etkisini azaltabilmek için kullanılan yöntemlerinde sürdürülebilir olması gerekmektedir. Biyodizel üretiminde gıdasal yağların kullanılması yă̆ fiyatlarının artmasına ve yağ karaborsasına sebep olduğundan yenilenemeyen alternatif kaynaklardan biyodizel üretilmesi gerekmektedir(Oğuz Yunus et al., 2010). Karbondioksit salınımını azaltmak için $\mathrm{CO}_{2}$ 'nin çimento üretiminde kullanılması gibi çözümler olsa da bu yöntemler pek sürdürülebilir görünmemektedir (Lopamudra et al., 2015). Bunlara ek olarak nüfus artışına bağlı oluşan atıklarında sürdürülebilir ve uygulanabilir şekilde yönetilebilmesi gerekmektedir. Özellikle akarsu ve içme sularına karışan atık yağların kontrol edilmesi, şehirsel organik kökenli katı atıkların düzenli yönetimiyle istenmeyen koku, görüntü ve bulaş riskinin azaltılması gerekmektedir. Sürdürülebilir alternatif kaynakların eldesinde hem karbondioksit salınımı azaltılmının hem de atıkların faydalı şekilde bertarafı Küresel 1sınmanın düzene girmesine yardımcı olabilmektedir. $\mathrm{Bu}$ amaçlara uygun olarak kullanılan yöntemlerden biriside Algler gibi basit canlıların kullanılmasıdır. Algler değişik şartlar altında hayatlarına devam edebilen türlerine göre içeriklerinde yağ ve protein miktarları farklılık gösteren tek hücreli sucul canlılar olarak bilinmektedir ve yüksek karbondioksit tüketme özelliğine sahiptirler. Bu özelliklerinden dolayı yoğun şekilde araştırılmaktadır. Yapılan çalışmalarda, yüksek sıcaklıklarda yapısı bozularak biyo yağ elde edilip sürdürülebilir enerji kaynağı olarak kullanılmaktadır (Hasan et al., 2020; Mehran et al., 2018; Wenhua et al., 2017). Ayrıca, hidrotermal gazlaştırma(Farid et al., 2016), fenolik bileşikler ve antioksidan kaynağı(Karolina et al., 2020), hayvan besini olarak(Dineshbabu et al., 2019) veya organik gübre üretimi, sulardaki nitrat ve fosfatların giderilmesi (Uthirapandi et al., 2018; Zamalloa et al., 2013), ağır metallerin uzaklaştırılması (A. Ruiz et al., 2012) gibi çok farklı amaçlar için kullanılabildikleri görülmektedir. Algler yaşam şartlarına bağlı olarak üretim maliyetlerinin düşük olması ve normal yapraklı ağaçlara göre $\mathrm{CO}_{2}$ kullanımının 10-100 kat fazla oluşu onlara duyulan ilginin daha da artmasını sağlamaktadır(Junchen et al., 2020). Yapılan araştırmalarda alglerin yaşamları için gerekli olan sıcaklığın, 1şık miktarının ve farklı şekildeki fotobiyoreaktör tasarımlarının Alglerin büyümeleri üzerine etkileri olduğu görülmektedir (Junchen et al., 2020; Satendra Pal Singh \& Priyanka, 2015). Alglerin gelişimlerinde $\mathrm{CO}_{2}$ çözünürlüğünün önemli olmasından dolayı bu alanda birçok çalışma yapılmıştır. Alglerin özellikle atıklarla beslenmesi ve bunların büyüme üzerine etkilerinin incelenmesi alglerin genel karakterlerinin belirlenmesinde ve atıklardan faydalı ürünler elde edilmesi günümüzde yaşadığımız çevresel felaketlerin çözümüne katk1 sağlayacağı düşünülmektedir. Yapılan çalışmadan elde edilebilen sonuçlar ile hem küresel 1sınmaya sebep olan karbondioksit salınımı azaltılmış olacak hemde doğal protein atıklarından elde edilen amino asitler Algerin gelişimlerinde kullanılarak faydalı ürünlere dönüştürülmüş olacaktır. $\mathrm{Bu}$ bağlamda çalışmanın sürdürülebilir ve alternatif kaynakların elde edilmelerine katkı sağlayacağı düşünülmektedir.

Yapılan bu çalışmada, laboratuvar boyutlarında iki adet hava karıştırmalı foto-biyo reaktör kullanılarak "Cladhopora glomerata"nın büyümesine farklı dalga boylarındaki 1şığın etkileri ve atık protein kaynaklarından elde edilmiş \%17 amino asid içeren besin kaynağı ile beslemenin alglerin kütlesel artışları üzerine etkileri araştırılmıştır. Deneysel çalışmalardan elde edilen sonuçlara göre, $425 \mathrm{~nm}$ (mor 1şık) dalga boyuna sahip 1şığın diğer dalgaboylarından daha etkin olduğu ve doğal kaynaklı amino asidin geleneksel besleme $(\mathrm{N}, \mathrm{P}, \mathrm{K})$ ortamına göre daha etkin olduğu görülmüştür.

\section{Materyal ve Metot}

\subsection{Materyal}

Besi yeri oluşturmak için N/P/K (kütlece 15-N/15-P/15-K) Toros Gübre üretimi gübre kullanılmıştır. Deneylerde kullanılan $\% 17$ doğal kökenli amino asit içeren besi ortamı ise Serin Arge limited şirketinden satın alınmıştır. Deneyde kullanılan Cladhopora glomerata kültürü Gümüşhane İli merkezi Bağlarbaşı mevkiindeki doğal ortamı olan Harşit çayından Eylül ayında temin edilmiştir. Fotobiyoreaktörler, 4 Litre hacimde iki adet polimer molekül ağırlığı $350,000.00 \mathrm{M}_{\mathrm{w}}$ olan, düşük yüzey pürüzüne sahip 0.0010-0.007 $\mu \mathrm{m}$ poly(methyl methacrylate) şeffaf silindirik polimerden üretilmiştir. Reaktörlerden birisi deney diğeri ise kontrol grubu olarak kullanılmıştır. Reaktör boyutları $9 \mathrm{~cm}$ çapında $100 \mathrm{~cm}$ uzunluğunda olarak tasarlanmış ve reaktörün dış ortam ile yalıtımı sağlamak için siyah renkli sıkıştırılmış ahşap yapıdan imal edilen 40L'lik kabin kullanılmıştır. Hava beslemesi için $4 \mathrm{~W}$ gücünde $2 \times 4.5 \mathrm{~L} / \mathrm{dk}$ Hailea Aco-6604 motor ve reaktör tabanında sabitlenmiş $3 \mathrm{~cm}$ büyüklügüunde küresel hava dağıtıcı taş disk kullanılmıştır buna bağlı reaktördeki $\mathrm{CO}_{2}$ miktarı $36.63 \times 10^{-4} \mathrm{~L} / \mathrm{dk}$ olarak belirlenmiştir. Işıklandırma için RGB (54 led/m) sistemi $425 \mathrm{~nm}$ ( $\sim 670-750 \mathrm{THz})$ dalga boyunda 1şık yaymaktadır ve $94 \mathrm{~W}(12 \mathrm{~V}$ 7.8 A) gücünde iki reaktör içinde eşit ve spiral olarak 4200 lüx 1şık sağlayacak şekilde hesaplanılmıştır. Işıklandırma süresi modeli için (16:8) 16 saatlik 1şıklandırmada gündüz modeli yapılarak 8 saat gece karanlığı gece modeli uygulanmıştır. Alglerin incelenmesinde Nikon E200 marka mikroskoba bağlı Nikon fotograf makinasının 1-J1 modeli kullanılmıştır.

\subsubsection{Metod}

Yapılan çalışmada besi ortamı için reaktörlere 4.5 L saf su ilave edilerek hazırlanmıştır. Çalışmalar 21-23 ${ }^{\circ} \mathrm{C}$ arasında sıcaklık kontrollü olarak yapılmıştır. Yapılan çalışmalar için kulanılan Algler doğal ortamlarından alındıktan sonra 5 defa saf 
su ile yıkandıktan sonra $40{ }^{\circ} \mathrm{C}$ deki etüvde 24 saat boyunca bekletildikten sonra $20 \mathrm{mg}$ tartılarak reaktöre ilave edilmiştir(Minoo \& Palsson, 1991). Reaktörlerde 1şılandırma yapay gün dönemi (16 saat açık), gece dönemi (8 saat kapalı) olarak yapılmış ve inkübasyon 7 gün boyunca gözlemlendikten sonra oluşan algler hasat edilip süzgeç kâğıdında süzülüp 24 saat boyunca etüvde $40{ }^{\circ} \mathrm{C}$ bekletildikten sonra tartım alınarak kütle artışı belirlenmiştir (Wahidin et al., 2013). Alglerin beslenmelerinde deniz suyu tuzluluk oranı temel alınarak; N/P/K ağırlık olarak \%15/15/15 gübresinden $20 \mathrm{gr} / 4.5 \mathrm{~L}$, doğal amino asit kaynağı (Glisin, Threonin, Lizin, Prolin, Tirozin, Aspartik a., Alanin, Valin, Arginin, Methionin, Triptofan, Glutamik a., Serin, Lösin, Histidin, Fenilalanin, Glutamin) ise 10gr/4.5L seyreltilerek kullanılmıştır.

\section{Araştırma Sonuçları ve Tartışma}

Biyoreaktörler kullanılan organizmaların çeşidine göre ihtiyaç duyduğu yaşam şekli farklılık göstermektedir. Yapısında klorofil bulunan ve fotosentez yapabilen Alglerin fotosentetik etkinliklerini artırmaları için tasarlanan hava kaldırmalı fotobiyo reaktörlerde en önemli noktalar; 1şı miktarı, beslenmeyle birlikte karıştırma şeklidir(Bahadur et al., 2013; Franz et al., 2000; Vree et al., 2015). Karıştırma şekline bağlı olarak suda çözünmüş karbondioksit miktarının artırılması ve fotosentez sonucu artan oksijen miktarının uzaklaştırılması ayrıca Alglerin hareket ettirilerek ihtiyaç duydukları ışığa ulaşmaları hedeflenmektedir (Jianke et al., 2014; Molina et al., 2001). Bu sebeple atmosferik $\mathrm{CO}_{2}$ çözünürlüğünü artırmak için çok farklı reaktör tasarımları ve çalışmalar yapılmaktadır(Dalle \& Arnaudis, 2017; Franz et al., 2000; Minoo \& Palsson, 1991). Bunlara bağlı olarak Junchen ve arkadaşları tarafından tasarlanan reaktörde kabarcı̆̆ın hızını yavaşlatarak $\mathrm{CO}_{2}$ çözünürlüğünü artırabilmek için boru şeklindeki reaktörde spiral ayırıcılar kullanılarak kabarcıkların hızı \%190 yavaşlatılmış ve verim \% 40 oranında artırılmıştır(Junchen et al., 2020). Buna benzer bir başka çalışmada ise düz panel tipli hava kaldırmalı biyoreaktörde reaktör tabanına paralel düz plakalar konup hava kabarcıklarının reaktör içersinde aldığı yol uzatılarak reaktör içersindeki atmosferik $\mathrm{CO}_{2}$ çözünürlüğü artırılmıştır(Jörg et al., 2001; Lin-lin et al., 2014).

Tablo-1 Fotobiyoreaktörde Işı̆̆ın Büyüme Üzerine Deney Şartları

\begin{tabular}{|c|c|c|}
\hline Deney Şartları & $\begin{array}{c}\text { Deney grubu } \\
(1 \text { şılı) }\end{array}$ & $\begin{array}{c}\text { Kontrol grubu } \\
(1 \text { şıssız })\end{array}$ \\
\hline Işık & Mor(425 nm) & Güneş Işı̆̆ 1 \\
\hline Besi & \multicolumn{2}{|c|}{$\mathrm{N} / \mathrm{P} / \mathrm{K} 20 \mathrm{~g} / \mathrm{L}$} \\
\hline Debi & \multicolumn{2}{|c|}{$2.5 \times 10^{5} \mathrm{~m}^{3} / \mathrm{s}$} \\
\hline pH & \multicolumn{2}{|c|}{$8.3($ bazik $)$} \\
\hline Sicaklık & $20^{\circ} \mathrm{C}-23.1^{\circ} \mathrm{C}$ & $20^{\circ} \mathrm{C}-21^{\circ} \mathrm{C}$ \\
\hline Kültür & \multicolumn{2}{|c|}{ Cladhopora glomerata $(100 \mathrm{mg})^{2}$} \\
\hline
\end{tabular}

Alg yetiştirmek için, yatay veya dikey borusal fotobiyoreaktörler, düz panel tipli fotobiyoreaktörler gibi veya bunların modifiye edilmeleriyle elde edilen fotobiyoreaktörler kullanılmaktadır(Vree et al., 2015). Panel tipli ve köşegene sahip reaktörlerde köşe kısımların karışımı, beslenmesi ve ışık ihtiyacı pek karşılanamamaktadır. $\mathrm{Bu}$ sebeplerle yapılan çalışmada borusal silindirik düşük yüzey pürüzüne sahip fotobiyoreaktör kullanılmıştır ve yapılan uygunlaştırma çalışmalarında Alglerin strese girmeden büyüdükleri görülmüştür. $\mathrm{Bu}$ sebeple yapılan çalışmada daha çok atıkların besin olarak Alglerin büyümeleri üzerine odaklanılmıştır (Bahadur et al., 2013; Mohsenpour \& Willoughby, 2013). Alglerin büyümesinde ve hücre içi yapılarında meydana gelen kimyasalların içeriğine etki eden en önemli noktalardan bir diğeri ise yeterli 1şı̆̆ın olmasıdır(Kim et al., 2014; Molina et al., 2001). Bu sebeple, hem gün 1şığ kullanılarak üretim yapılan reaktörler hem de kapalı alanlarda üretim için tasarlanmış reaktörler Alglerin 1şık kaynaklarına yeterince ulaşmaları göz önünde bulundurularak tasarlanmıştır. Farklı 1şık kaynaklarından beslenen Alglerdeki hücre içi yağ asidi ve amino asit içerikleri değişiklik gösterebilmektedir(James et al., 1989; Michael et al., 2015; Mohsenpour et al., 2012; Wahidin et al., 2013; Yoshioka et al., 2012).

\begin{tabular}{|c|c|c|}
\hline Deney Şartları & Deney grubu (1şıklı) & $\begin{array}{c}\text { Kontrol } \\
\text { grubu(1̧̧ıksız) }\end{array}$ \\
\hline Işık & $425 \mathrm{~nm}$ Mor Işık & Güneş Işı̆̆ 1 \\
\hline Besi & 17 Farklı Aminoasit $(10 \mathrm{gr} / 4.5 \mathrm{~L})$ \\
\hline Debi & \multicolumn{2}{|c|}{$2.5 \times 10^{5} \mathrm{~m}^{3} / \mathrm{s}$} \\
\hline pH & \multicolumn{2}{|c|}{$8.3($ bazik $)$} \\
\hline Sicaklık & $20^{\circ} \mathrm{C}-23.1^{\circ} \mathrm{C}$ & $20^{\circ} \mathrm{C}-21^{\circ} \mathrm{C}$ \\
\hline Kültür & Cladhopora glomerata $(100 \mathrm{mg})$ \\
\hline
\end{tabular}

Tablo-2 Fotobiyoreaktörde Beslenmenin Büyüme Üzerine Deney Şartları

Bunların dışında gün 1şı̆̆ından faydalanmak için tasarlanan ve 1şık kaynağı reaktörün içinden sağlanan farklı çalışmalarda mevcuttur(Mohsenpour \& Willoughby, 2013). Satthong ve arkadaşlarının yaptığı çalışmada Chlorella vulgaris'in floresan 1şık ve farklı dalga boylarındaki (light emitting diodes(LED)) gelişimleri incelemişler ve LED 1şık kaynağının floresana göre daha iyi büyüme etkisi gösterdiği sonucuna ulaşmışlardır(Satthong et al., 2019). Benzer bir diğer çalışmaya göre Chlorella vulgaris en iyi gelişimini LED 1ş1kta hücre büyüklüğüne mavi 1şıkta ve hücre çoğalmasını ise kırmızı $1 s ̧ 1 k$ altında göstermiştir (Kim et al., 2014). Önceki çalışmalardan elde edilen sonuçlara göre; Alglerin büyümesinde sabit dalga boyunun ve iki farklı dalgaboyunun karışımının aynı anda uygulanmasıyla elde edilen sonuçlar, karışık dalga boyunda diğer dalga boylarına göre daha yüksek verim elde edildiğini göstermiştir(Tae Hyeong et al., 2013). 


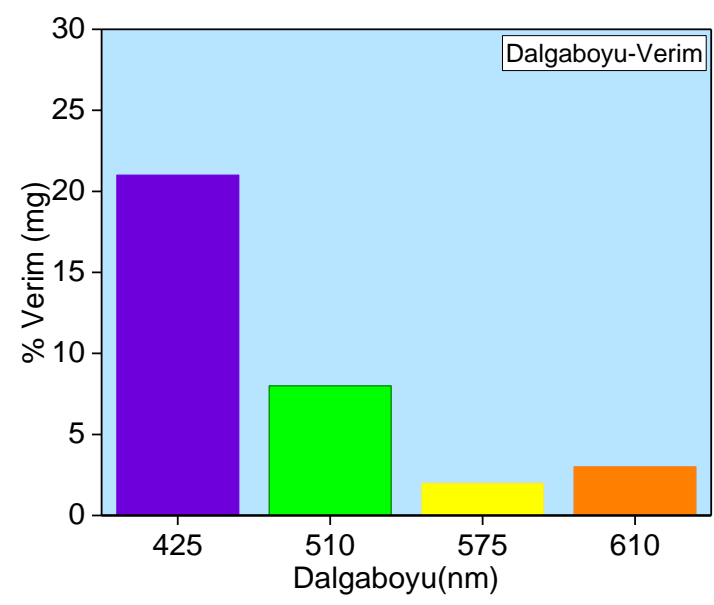

\section{Grafik-1 Dalga Boyu Büyüme ilişkisi}

$\mathrm{Bu}$ sebeple yapılan deneysel çalışmalarda, en uygun 1 şı kaynağının dalgaboyunu belirlemek için sarı 1şık (575 nm), yeşil 1ş1k $(510 \mathrm{~nm})$, turuncu 1ş1k $(610 \mathrm{~nm})$ ve mor 1 ş1k(425 nm) gibi farklı dalga boylarındaki 1şık kaynakları kullanılarak bu 1şıkların Cladhopora glomerata'nın gelişmeleri üzerine etkileri de araştırılmıştır (Grafik-1). Önceki çalışmalara paralel olarak Cladhopora glomerata'nın en iyi gelişimi $425 \mathrm{~nm}$ dalgaboyuna sahip mor 1 şıtkta elde edilmiş ve diğer çalışmalarda aynı dalga boyu kullanılmıştır (Mohsenpour et al., 2012; Molina et al., 2001; Satthong et al., 2019; Satendra P. Singh \& Singh, 2015; Tae Hyeong et al., 2013). Yapılan bu çalışmada tasarlanan reaktörde 1şık kaynağ1 silindirik reaktörün çevresinden sağlandığı için 1şı̆̆ eşit miktarda almıştır. Mor 1şık kullanılarak elde edilen deneysel sonuçlara göre gün ışığında aynı besi şartları altındaki örnek \% 100 kütlesel artış göstermiştir (Tablo-1).

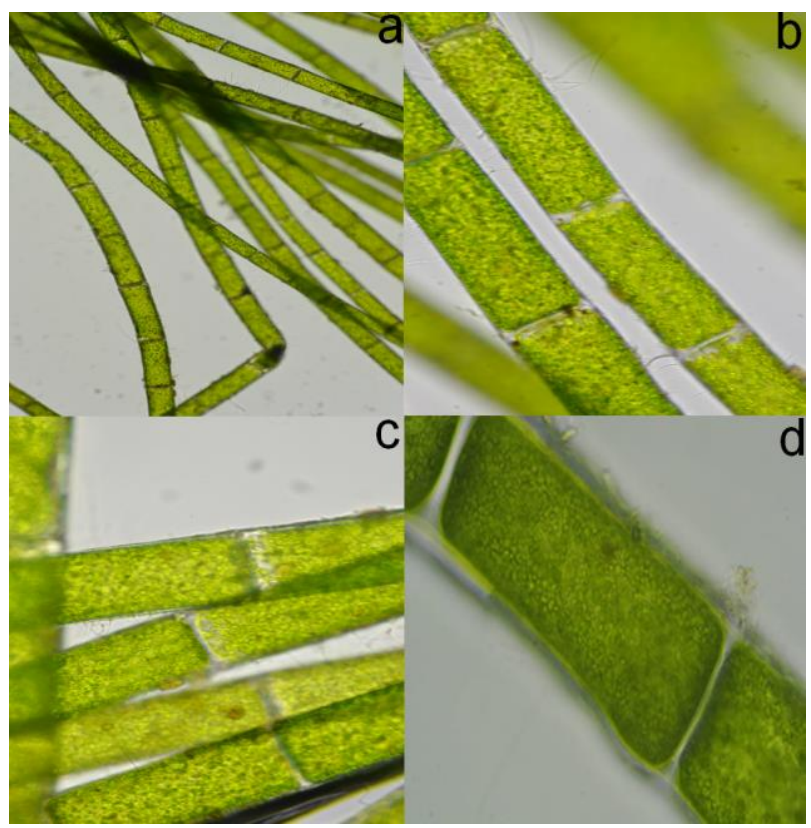

Şekil-1 Cladhopora glomerata 'nın Mikroskop Görüntüleri

Alglerin farklı dalga boylarındaki gelişimleri ve hücre içi yağ asidi içerikleri farklılık göstermektedir. Alglere uygulanan 1 şı kaynaklarının etkilerine benzer şekilde, Algerin farklı beslenmelerine bağlı olarak büyümeleri de değişiklik göstermektedir. Alglerin büyümelerinde beslemenin etkileri fosfat, azot ve potasyum gibi besilerle araştırılmış olsa da bunların dışında Alglerin gelişmek için vitaminlere de ihtiyaç duyduğu anlaşılmıştır. Beslenme farklılıklarına göre Alglerin yağ asidi içerikleri ve kuru ağırlıkları değişmektedir (Breuer et al., 2012; Schmidt et al., 2016; Sun et al., 2014; M. Warren et al., 2007).

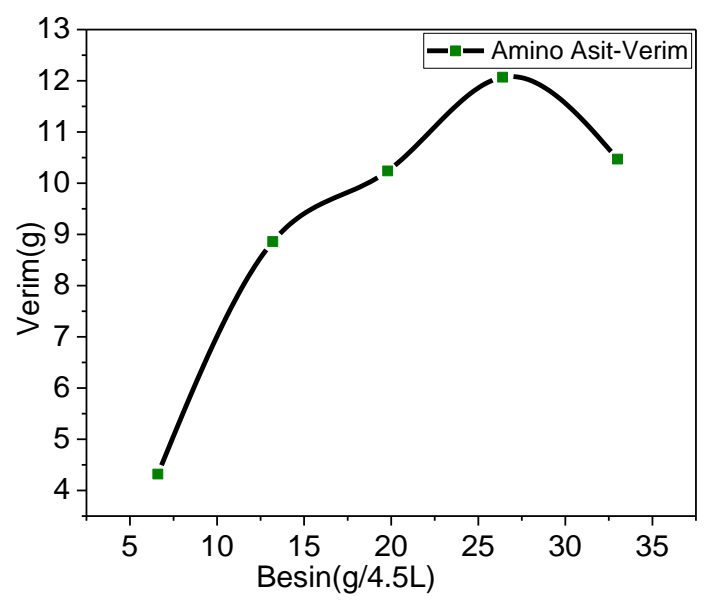

Grafik-2 Alglerin Beslenme -Verim Grafiği

Bu çalıșmaların dışında Alglerin beslenmede farklı stratejiler geliştirerek bazı bakteri türleri ile B12 gibi vitaminlerini karşılamak için ortaklaştıkları bulunmuştur(M. Warren et al., 2007). Elde edilen sonuçlara göre, Alglerin büyümelerinde sadece inorganik tuzlar değil vitaminler ve benzer moleküllerinde önemli rol oynadığı açıkca görülmektedir. $\mathrm{Bu}$ sebeple farklı besi ortamlarında gelişen Alglerin büyüme hızları farklılık gösterebilmektedir (Daume et al., 2003; Feng et al., 2012; Gobler et al., 2007; James et al., 1989).

Önceki çalışmalar incelendiğinde Alglerin büyüme ve gelişmelerinde sadece inorganik tuzların ve vitaminlerin etkin rol oynamadığı hatta glutamik asit ile beslenen Alglerde de büyümede gelişme görülmüştür(Abdelhakeem et al., 2019). Bu verilere dayanarak yapılan çalışmada farklı derişimlerde amino asid kullanılarak fotobiyoreaktörde aynı şartlar altında Cladhopora glomerata'nın kütlesel büyümesi incelenmiştir (Tablo-2). Amino asit kaynağı olarak beslenme amaçlı kullanılamayan kıl, tüy, sakatat gibi protein kaynaklarından elde edilmiş içerisinde \% 17 oranında amino asit içeren besi kullanılmıştır. Amino Asit içeriği doğal protein kaynaklarından elde edildiği için oransal olarak diğer canlılarla eşit yüzdeye sahip olduğundan dolayı herhangi bir uyumsuzluk görülmemiştir(Şekil-1). Kontrol grubu ile birlikte yapılan çalışma sonuçlarına göre 7 günlük süreç sonucunda Alglerin diğer şartlara oranla mükemmel gelişim gösterdikleri anlaşılmıştır. Amino Asitlerin miktarlarının artışına bağlı olarak en uygun derişimin $26.4 \mathrm{~g} / 4.5 \mathrm{~L}$ olduğu görülmektedir. $\mathrm{Bu}$ derişimden sonra beslenmede doygunluğa ulaşarak gelişim hızının düşmeye başladığ1 görülmüştür(Grafik-2).

Yapılan çalışmalarda bulunan bir diğer ilginç sonuç ise Alglerin doğal ortamlarından alındığında görüntülenen Protozoa'lardır (Şekil-2) (Finlay \& Esteban, 2013; A. Warren et al., 2016). 


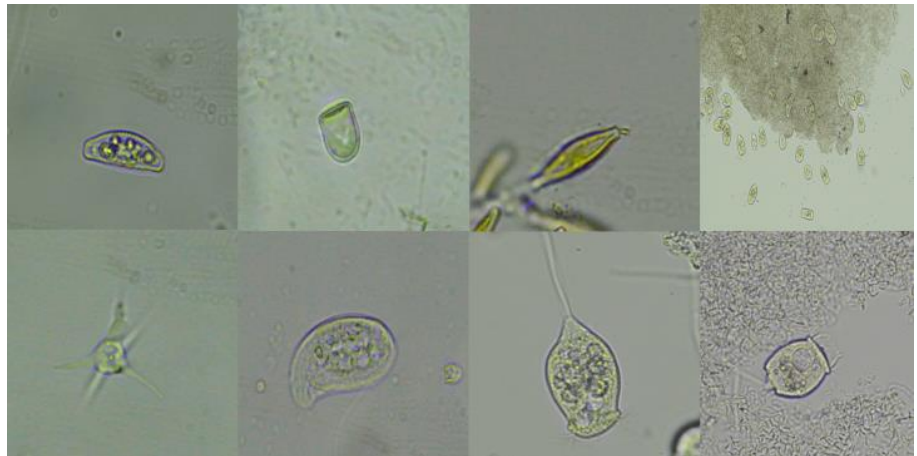

Şekil-2 Protozoaların mikroskop görüntüleri

Yapılan çalışmalarda Protozoaların bulunduğu ortamlarda Alglerin gelişim göstermediği ve belirli bir süre sonunda hücre duvarlarının parçalandığı görülmüştür. Sonuçta, yapılan detaylı incelemelerde ise Protozoaların Alglerin hücre duvarını parçalayarak yaşamına son verdiği görülmüştür. Alglerin Protozoalarla rekabetçi bir yaşam biçimi gerçekleştirdiği ve Alglerin gelişimlerini engellediği görülmüştür. Diğer bir çalışma konusu ile ilgili çalışmalar devam etmektedir.

\section{Sonuç}

Ekolojik dengenin sağlanabilmesi için sürdürülebilir çözümlerin bulunması gerekmektedir. Bu çözümler ise öncelikle Küresel 1sınmaya sebep olan sera gazı $\mathrm{CO}_{2}$ miktarının azaltılmasıdır. Algler yaşam şartlarının kolay olması bol bulunmaları ve yüksek $\mathrm{CO}_{2}$ tüketme kapasitesine sahip canlılar olarak alternatif enerji üretiminde ve benzer birçok alanda kullanılmaktadır. Yapılan çalışmada Cladhopora glomerata'nın yaşam şartlarına uygun hava karıştırmalı fotobiyoreaktör başarılı şekilde imal edilmiştir. Cladhopora glomerata'nın gelişim gösterdiği en uygun 1 şı (425nm mor 1şık) belirlenerek gün 1şığ1 ile karşılaştırılmış, diğer dalgaboyları ve gün 1şığına göre gelişiminin daha yüksek olduğu gözlenmiştir. Bunun dışında atık protein kaynaklarından üretilen doğal kaynaklı Amino Asit karışımları kullanılarak Alglerin kütlesel gelişimleri üzerine etkileri incelenmiştir. Araştırmalarda Amino Asit miktarının artan değişimi ile Alglerin gelişimlerinin $26.4 \mathrm{~g} / 4.5 \mathrm{~L}$ derişime kadar doğru orantılı şekilde ve çok yüksek verimde gerçekleştiği görülmüştür.

Sonuçta atık protein kaynakları kullanılarak Alglerin gelişimlerinin hızlandırılabildiği böylece hem atıkların faydalı bertarafının gerçekleştirilebileceği hem de sera gazının etkilerinin azaltılarak Alternatif sürdürülebilir çözümler üretilebileceği görülmüştür.

\section{Kaynakça}

A. Ruiz, M., Garcia, N. M., Romero, I., Seco, A., \& Ferrer, J. (2012). Microalgae cultivation in wastewater: Nutrient removal from anaerobic membrane bioreactor effluent. Bioresource Technology, 126, 247-253.

Abdelhakeem, E., Abou-Zaid, A., \& Eissa, M. A. (2019). Thompson Seedless Grapevines Growth and Quality as Affected by Glutamic Acid, Vitamin B, and Algae. Journal of Soil Science and Plant Nutrition, 19, 725-733.

Bahadur, A., Zubair, M., \& Khan, M. B. (2013). Design, construction and evaluation of solarized airlift tubular photobioreactor. Journal of Physics: Conference Series, 439, 012036.

e-ISSN: 2148-2683
Bedoi, R., Juri, F., Cosi, B., Puksec, T., Cucek, L., \& Duic, N. (2020). Beyond energy crops and subsidised electricity e A study on sustainable biogas production and utilisation in advanced energy markets. Energy, 201, 117651.

Breuer, G., Lamers, P. P., Martens, D. E., Draaisma, R. B., \& Wijffels, R. H. (2012). The impact of nitrogen starvation on the dynamics of triacylglycerol accumulation in nine microalgae strains. Bioresource Technology, 124, 217-226.

Corrie, M., \& Fernando, D. S. (2020). Impacts of global warming on southern California's winegrape climate suitability. Advances in Climate Change Research, 11, 279-293.

Dalle, M. A., \& Arnaudis, J. (2017). France Patent No.: W. (PCT).

Daume, S., Long, B. M., \& Crouch, P. (2003). Changes in amino acid content of an algal feed species (Navicula sp.) and their effect on growth and survival of juvenile abalone (Haliotis rubra). Journal of Applied Phycology, 15, 201-207.

Dineshbabu, G., Goswamia, G., Kumara, R., Sinhaa, A., \& Das, D. (2019). Microalgae-nutritious, sustainable aqua- and animal feed source. Journal of Functional Foods 62, 103545.

Farid, S., Omid, N., \& Ahmad, T. (2016). Hydrothermal gasification of Cladophora glomerata macroalgae over its hydrochar as a catalyst for hydrogen-rich gas production. Bioresource Technology 222, 232-241.

Feng, P., Deng, Z., Fan, L., \& Hu, Z. (2012). Lipid accumulation and growth characteristics of Chlorella zofingiensis under different nitrate and phosphate concentrations. Journal of Bioscience and Bioengineering, 114, 405-410.

Finlay, B. J., \& Esteban, G. F. (2013). Protozoa. In (Vol. 6). Elsevier: Encyclopedia of Biodiversity.

Franz, B., Retze, A., Schmid-Staiger, U., Trösch, W., \& Zastrow, A. (2000). E. P. Office.

Gobler, C. J., Norman, C., Panzeca, C., Taylor, G. T., \& SañudoWilhelmy, S. A. (2007). Effect of B-vitamins (B1, B12) and inorganic nutrients on algal bloom dynamics in a coastal ecosystem. Aquatic Microbial Ecology, 49, 181-194.

Hasan, N., Ahmad, T., \& Sajedeh, J. (2020). Investigating the influence of acid washing pretreatment and $\mathrm{Zn} /$ activated biochar catalyst on thermal conversion of Cladophora glomerata to value-added bio-products. Energy Conversion and Management 225, 113392.

James, C. M., Al-Hinty, S., \& Salman, A. E. (1989). Growth and m3 Fatty Acid and Amino Acid Composition of Microalgae Under Different Temperature Regimes. Aquaculture, 77, $337-$ 351.

JeanCalleja, A., Kathleen, E., \& Neville, C. (2020). The effect of global warming on mortality. Early Human Development, in press.

Jianke, H., Li, Y., Wan, M., Yan, Y., Feng, F., Qu, X., Wang, W. (2014). Novel flat-plate photobioreactors for microalgae cultivation with special mixers to promote mixing along the light gradient. Bioresource Technology, 159, 8-16.

Jörg, D., Uebele, A., Retze, A., Trösch, W., \& Schmid-Staiger, U. (2001). A novel airlift photobioreactor with baffles for improved light utilization through the flashing light effect. Journal of Biotechnology, 92, 89-94.

Junchen, X., Jun, C., Xin, K., Xu, J., \& Yang, W. (2020). Developing a Spiral-Ascending CO2 Dissolver to Enhance CO2 Mass Transfer in a Horizontal Tubular Photobioreactor for Improved Microalgal Growth. ACS Sustainable Chemistry \& Engineering, 8(51), 18926-18935.

K. M. Nazmul, I., Kenway, S. J., Marguerite, A. R., Ka Leung, L., $\&$ Thomas, W. (2021). A review of the water-related energy 
consumption of the food system in nexus studies. Journal of Cleaner Production, 279, 123414.

Karolina, K., Bogusława, Ł., \& Piotr Paweł, W. (2020). Isolation and determination of phenolic compounds from freshwater Cladophora glomerata. Algal Research, 48, 101912.

Kim, D. G., Lee, C., Park, S.-M., \& Choi, Y.-E. (2014). Manipulation of light wavelength at appropriate growth stage to enhance biomass productivity and fatty acid methyl ester yield using Chlorella vulgaris. Bioresource Technology 159, 240-248.

Lin-lin, W., Tao, Y., \& Mao, X.-z. (2014). A novel flat plate algal bioreactor with horizontal baffles: Structural optimization and cultivation performance. Bioresource Technology 164, 20-27.

Lindsey, R. (2021). Climate Change: Atmospheric Carbon Dioxide. Retrieved from

Lopamudra, P., Bhattacharjee, V., Mitra, R., Bhattacharya, I., \& Chowdhury, R. (2015). Biosequestration of $\mathrm{CO}_{2}$ using power plant algae (Rhizocloniumhieroglyphicum JUCHE2) in a Flat Plate hotobio-Bubble-Reactor -Experimental and modeling. Chemical Engineering Journal, 275, 381-390.

Mehran, P., Hamoon, J., Maryam, P., Reza, G., \& MohammadAli, A. (2018). Hydrothermal liquefaction of Gracilaria gracilis and Cladophora glomerata macro-algae for biocrude production. Bioresource Technology, 250, 26-34.

Michael, C., Ninno, M. d., Gross, M., \& Wen, Z. (2015). Use of wavelength-selective optical light filters for enhanced microalgal growth in different algal cultivation systems. Bioresource Technology, 179, 473-482.

Minoo, J., \& Palsson, B. (1991). High-Density Photoautotrophic Algal Cultures: Design, Construction, and Operation of a Novel Photobioreactor System. Biotechnology and Bioengineering, 1182-1189.

Mohsenpour, S. F., Richards, B., \& Willoughby, N. (2012). Spectral conversion of light for enhanced microalgae growth rates and photosynthetic pigment production. Bioresource Technology, 125, 75-81.

Mohsenpour, S. F., \& Willoughby, N. (2013). Luminescent photobioreactor design for improved algal growth and photosynthetic pigment production through spectral conversion of light. Bioresource Technology, 142, 147-153.

Molina, E. G., Fernandez, J., Acien, F. G., \& Chisti, Y. (2001). Tubular photobioreactor design for algal cultures. Journal of Biotechnology 92, 113-131.

Oğuz Yunus, S., Mustafa, Ö., Hasan, S., Serin, S., \& Kadir, A. (2010). Biodiesel production from ricinus communis oil and its blends with soybean biodiesel. Strojniški vestnik - Journal of Mechanical Engineering, 56(12), 811-816.

Patel, R. P., Nagababu, G., Kumar, S. V. V. A., M., S., \& Kachhwah, S. S. (2020). Wave resource assessment and wave energy exploitation along the Indian coast. Ocean Engineering 217, 107834.

Satthong, S., Saego, K., Kitrungloadjanaporn, P., Nuttavut, N., Amornsamankul, S., \& Triampo, W. (2019). Modeling the effects of light sources on the growth of algae. Advances in Difference Equations, 170.

Schmidt, J. J., Gagnon, G. A., \& Jamieson, R. C. (2016). Microalgae growth and phosphorus uptake in wastewater under simulated cold region conditions. Ecological Engineering 95, 588-593.

Shuirong, T., Cheng, W., Hu, R., Guigue, J., Hattori, S., Tawaraya, K., Hasegawa, T. (2021). Five-year soil warming changes soil $\mathrm{C}$ and $\mathrm{N}$ dynamics in a single rice paddy field in Japan. Science of the Total Environment 756, 143845.
Singh, S. P., \& Priyanka, S. (2015). Effect of temperature and light on the growth of algae species: A review. Renewable and Sustainable Energy Reviews, 50, 431-444.

Singh, S. P., \& Singh, P. (2015). Effect of temperature and light on the growth of algae species: A review. Renewable and Sustainable Energy Reviews 50, 431-444.

Sun, X., Cao, Y., Xu, H., Liu, Y., Sun, J., Qiao, D., \& Cao, Y. (2014). Effect of nitrogen-starvation, light intensity and iron on triacylglyceride/carbohydrate production and fatty acid profile of Neochloris oleoabundans HK-129 by a two-stage process. Bioresource Technology, 155, 204-212.

Tae Hyeong, K., Lee, Y., Han, S.-H., \& Hwang, S.-J. (2013). The effects of wavelength and wavelength mixing ratios on microalgae growth and nitrogen, phosphorus removal using Scenedesmus $\mathrm{sp}$. for wastewater treatment. Bioresource Technology 130, 75-80.

Uthirapandi, V., Suriya, S., Boomibalagan, P., Eswaran, S., Ramya, S. S., Vijayanand, N., \& Kathiresan, D. (2018). Biofertilizer potential of seaweed liquid extracts of marine macro algae on growth and biochemical parameters of Ocimum sanctum Journal of Pharmacognosy and Phytochemistry, 7(3), 3528-2532.

Vree, J. H. d., Bosma, R., Janssen, M., Barbosa, M. J., \& Wijffels, R. H. (2015). Comparison of four outdoor pilot-scale photobioreactors. Biotechnology for Biofuels, 8, 215.

Wahidin, S., Idris, A., \& Shaleh, S. R. M. (2013). The influence of light intensity and photoperiod on the growth and lipid content of microalgae Nannochloropsis sp. Bioresource Technology, 129, 7-11.

Warren, A., Esteban, G. F., \& Finlay, B. J. (2016). Protozoa. In Thorp and Covich's Freshwater Invertebrates.

Warren, M., Deery, E., Warren, M., Croft, M., \& Smith, A. (2007). Algae acquire Vitamin B12 through a symbiotic relationship with bacteria. Nature, 438, 90-93.

Wenhua, G., Kefu, C., Jinsong, Z., Jun, X., \& Bin, W. (2017). Thermal pyrolysis characteristics of macroalgae Cladophora glomerata. Bioresource Technology, 243, 212-217.

Yaduvanshi, A., Bendapudi, R., Nkemelang, T., \& New, M. (2021). Temperature and rainfall extremes change under current and future warming global warming levels across Indian climate zone. Weather and Climate Extremes, 31, 100291.

Yoshioka, M., Yago, T., Yoshie-Stark, Y., Arakawa, H., \& Morinaga, T. (2012). Effect of high frequency of intermittent light on the growth and fatty acid profile of Isochrysis galbana. Aquaculture 338, 111-117.

Zamalloa, C., Boon, N., \& Verstraete, W. (2013). Decentralized two-stage sewage treatment by chemical-biological flocculation combined with microalgae biofilm for nutrient immobilization in a roof installed parallel plate reactor. Bioresource Technology 130, 152-160.

Zhang, Q. L. Y., Mieghem, A. V., Chen, Y.-C., Yu, N., Yang, Y., \& Yin, H. (2020). Design and experiment of a sun-powered smart building envelope with automatic control. Energy \& Buildings, 223, 110173.

Zhoua, B., Or, S. W., Chan, K. W., Duan, H., Wu, Q., Wang, H., \& Meng, Y. (2021). Short-term prediction of wind power and its ramp events based on semisupervised generative adversarial network. Electrical Power and Energy Systems $125,106411$. 